\title{
AMBIVALÊNCIAS DE PRÁTICAS ESPACIAIS AUTO-ORGANIZADAS EM DISPUTAS PELA DEMOCRATIZAÇÃO DA PRODUÇÃO DO ESPAÇO
}

\section{AMBIVALENCES OF SELF-ORGANIZED SPATIAL PRACTICES WITH IN DISPUTES FOR DEMOCRATIZING THE PRODUCTION OF SPACE}

\author{
LÍGia Milagres \\ Universidade Federal de Minas Gerais, Programa de Pós-Graduação em Arquitetura e Urbanismo, \\ Belo Horizonte, Minas Gerais, Brasil
}

\begin{abstract}
R E S U M O : Este artigo tem por objetivo discutir as ambivalências de práticas espaciais auto-organizadas em situações de disputa pela democratização da produção do espaço urbano. Tendo em vista o papel dessas práticas na construção de uma democracia urbana radical, o texto analisa o processo de decisão sobre o espaço do antigo aeroporto Tempelhof (Berlim). São postos em relevo, para esse caso, alguns aspectos do conflito entre práticas auto-organizadas e planejamento institucional no contexto neoliberal. Conclui-se que, apesar dos entraves, essas práticas contribuem para ampliar as condiçóes de discussão, decisão e ação coletiva de moradores urbanos. A análise desse tipo de conflito pode informar a crítica do planejamento urbano, assim como a imaginação de processos e instrumentos que facilitem a expansão do campo de ação dos moradores urbanos.
\end{abstract}

P A L A V R A S - C H A V E : planejamento urbano; auto-organização; processos de decisão; democracia radical; espaço cotidiano.

A B S T R A C T : The paper aims to discuss the ambivalences of self-organized spatial practices involved in disputes for democratizing the production of space. Considering the role of these practices in the construction of radical urban democracy, the paper critically analyses the decision making process regarding the space of the former Tempelhof airport (Berlin). The paper highlights a number of aspects concerning the conflict between self-organized spatial practices and institutional urban planning in the neoliberal context. We conclude that, despite the limitations, such practices contribute towards broadening the conditions of collective discussion, decision and action on the part of urban dwellers. An analysis of this kind of conflict may provide information for criticism of urban planning, as well as for imagination in processes and tools that contribute to expanding the field of action for urban dwellers.

K E Y W O R D S : urban planning; self-organization; decision-making processes; radical democracy; everyday space.

DOI: https://doi.org/10.22296/2317-1529.2016v18n2p205 


\section{INTRODUÇÃO}

Nos últimos anos, a discussão sobre as implicações políticas de práticas espaciais insurgentes antagônicas ao capitalismo e ao Estado neoliberal vem crescendo, especialmente com a análise crítica de movimentos que tiveram visibilidade global, como o Occupy, em Nova York, e os protestos que se espalharam pela Turquia a partir da resistência em torno do parque Taksim Gezi, em Stambul. Diferentes autores discutem esses movimentos como expressôes de um processo de transformaçáo no modo de se produzir cidades. David Harvey (2012, p. 119, tradução da autora) aponta para o desafio de se entender a política e o potencial transformador desses "movimentos de oposição difusa que carecem de coerência política geral”. Já Mark Purcell (2013)

10 uso desse termo segue a proposta de Marcelo Lopes de Souza $(2013$, p. 16, 17), para o qual o termo com o hífen - diferentemente de "socioespacial" - explicita uma abordagem equivalente tanto do social quanto do espacial, não reduzindo o "social" a um termo que apenas qualifica a abordagem do espaço. Neste artigo, auto-organização sócio-espacial diz respeito tanto ao processo de auto -organização quanto às práticas espaciais desdobradas no contexto desse mesmo processo.

20 artigo foi escrito durante - desenvolvimento da pesquisa de doutorado, portanto, a contextualização da discussão aqui apresentada, o seu aprofundamento, assim como a descrição completa do caso do Tempelhof estão presentes na tese, cujo foco são os processos de auto-organização sócio-espacial e as práticas espaciais que lhes são intrínsecas. A pesquisa, intitulada Processos de auto -organização sócio-espacial: ambivalências e desafios em situações de disputa por poder de decisão, foi realizada sob orientação da professora Dr.a Ana Paula Baltazar dos Santos e defendida, em 2016, no Programa de Pós-Graduação em Arquitetura e Urbanismo da Universidade Federal de Minas Gerais. Parte da investigação foi desenvolvida em Berlim, no departamento de Sociologia Urbana e Regional (Stadt- und Regionalsoziologie) da Humboldt Universität zu Berlin, com financiamento da Capes. argumenta que eventos como o de Istambul são movidos por um desejo de liberdade e de responsabilidade sobre as questóes urbanas coletivas, contribuindo para disseminar a prática e a construçáo da democracia nas cidades. Na motivação de movimentos como esses, há o descontentamento de diversos grupos sociais frente às condiçôes de poder de decisão sobre a produção do espaço, que reflete a concentração de poder político e econômico em cidades do mundo inteiro.

Se se observa o cotidiano de qualquer grande cidade, pondo em relevo mobilizaçôes de menor visibilidade e menor escala, é possível identificar coletividades que buscam ampliar seu poder de decisão por meio da auto-organização e de práticas que partem do questionamento das condições de decisão sobre um determinado espaço ou porção urbana. A auto-organização sócio-espacial ${ }^{1}$ pode estar presente em diferentes práticas espaciais, como na ocupação de uma área abandonada para uso coletivo, na autoprodução de infraestruturas urbanas ou na resistência ao planejamento institucional por meio da elaboração de contrapropostas.

Como parte de uma pesquisa de doutorado em desenvolvimento, este artigo discute as ambivalências de práticas espaciais desenvolvidas por moradores urbanos sem a presença de uma instituição ou de um especialista na coordenação do processo. ${ }^{2}$ Tais práticas questionam a produção hegemônica do espaço, exercendo pressão para que se amplie o poder de decisão popular sobre certas áreas urbanas. Nesse sentido, elas se diferenciam de outras práticas que, apesar de também serem auto-organizadas, têm como foco a manutenção das condiçóes privilegiadas por parte de certos grupos sociais e caracterizam-se pela organização coletiva voltada para a defesa de interesses privados.

$\mathrm{O}$ argumento deste artigo é o de que certas práticas espaciais auto-organizadas, assim como movimentos de maior amplitude, são motivadas por um "desejo de democracia” (PURCELL, 2013, tradução da autora) e são agentes importantes no processo de construção de cidades radicalmente democráticas. São aqui analisadas práticas auto-organizadas por diferentes grupos de moradores urbanos no processo de decisão sobre o uso do espaço do antigo aeroporto Tempelhof, em Berlim. Para tanto, são apresentados alguns pressupostos antes do caso empírico.

Entende-se aqui que a construção de cidades radicalmente democráticas depende da ampliação do poder de discussão e de decisão sobre os espaços urbanos, bem como de sua alteraçáo material de forma coletiva e autodeterminada ao longo do tempo. A possibilidade de autodeterminar coletivamente o espaço cotidiano urbano está no centro da noção de autogestão (autogestion), desenvolvida por Lefebvre (2009). Para o autor, a autogestão é uma prática que implica o fortalecimento dos laços associativos em todos os aspectos da vida social - no trabalho, em unidades territoriais, 
em cidades ou regiôes -, partindo de grupos que têm por objetivo "dominar as suas próprias condições de existência” (LEFEBVRE, 2009, p. 135, tradução da autora). Trata-se do exercício de um "contrapoder" e de uma luta prática, marcada por falhas e retrocessos. Essa abordagem considera a autogestâo como um processo ou movimento contínuo, e não como uma "operação técnica", um modelo administrativo a ser implementado, nem como uma "fórmula mágica" a ser aplicada. Tal como a democracia, a autogestão "nunca é uma condiçáo, mas uma luta" que evidencia as contradiçôes da organização política vigente (LEFEBVRE, 1976; 2009, p. 135, tradução da autora).

O princípio da autonomia coletiva é um dos elementos importantes para essa discussão. Ele implica uma organização social autodeterminada que garanta condiçôes iguais de participação nos processos de decisão a diferentes indivíduos e grupos (SOUZA, 2006a). Em outras palavras, trata-se de um princípio que pressupóe "a capacidade de os grupos definirem as normas que regem a produção do seu espaço" (KAPP et al., 2012). As práticas espaciais auto-organizadas, presentes em disputas pela democratização da produção de um determinado espaço, desenvolvem uma relação conflituosa com as práticas do planejamento urbano institucional. Esse conflito evidencia a assimetria de poder existente entre os moradores urbanos - especialmente aqueles com pouco poder político e econômico - e os agentes que podem decidir, oficialmente, questóes que são de interesse coletivo. Por sua vez, tal assimetria de poder é apontada por Souza (2010) como característica da produção do espaço em uma sociedade estruturada pela combinação entre capitalismo e democracia representativa, além de ser um dos elementos centrais para a manutenção das desigualdades econômicas e políticas.

A abordagem do conflito aqui mencionado - entre práticas espaciais auto-organizadas e planejamento institucional - não tem por objetivo dicotomizar as duas lógicas, mas discutir a relação entre diferentes formas de produção espacial e suas contradiçóes. Para essa abordagem, a perspectiva estadocritica, defendida por Souza (2012) no contexto de sua discussão sobre a relação dos movimentos sociais urbanos com o Estado, é uma ferramenta útil para a reflexão crítica da relação entre as práticas mencionadas em uma situação específica de disputa. A perspectiva estadocrítica considera a dialética entre "estrutura e conjuntura, estratégia e tática, curto prazo e longo prazo", tendo em vista as possibilidades de atuação dos movimentos junto do Estado, apesar do Estado e contra o Estado, sem que esses movimentos abandonem a crítica à heteronomia intrínseca a seu aparato (SOUZA, 2006b; 2012, p. 17).

A descrição e o exame crítico do caso do Tempelhof têm como base uma pesquisa de campo, com observação direta e entrevistas com integrantes dos grupos auto-organizados que atuaram no processo, um levantamento bibliográfico e uma análise dos estudos realizados por outros pesquisadores. A exploração desse caso evidencia aspectos ambivalentes das práticas espaciais auto-organizadas ao longo do processo de decisão e da sua relação com o planejamento institucional. Já a análise crítica oferece elementos relevantes para uma discussão das possibilidades, das ambivalências e dos desafios do papel dessas práticas no processo de democratização radical da produção do espaço. Busca-se compreender até que ponto tais práticas são capazes de criar e sustentar arranjos alternativos que ampliem as condições de atuação coletiva dos moradores urbanos na produção do espaço. 


\section{PRÁTICAS ESPACIAIS AUTO-ORGANIZADAS NO PROCESSO DE DECISÃO SOBRE O CAMPO DO TEMPELHOF}

3 Tempelhofer Feld (campo do Tempelhof) é o modo como o espaço livre do aeroporto é chamado em Berlim.

4 Como a discussão deste artigo enfoca as práticas auto-organizadas e seus pontos de contato com o planejamento urbano, a dimensão institucional da política urbana de Berlim não é abordada em profundidade, ainda que algumas de suas características sejam mencionadas quando diretamente relacionadas ao caso examinado.
Relativamente noticiado, o caso do Tempelhofer Feld ${ }^{3}$ ficou conhecido como aquele em que a populaçáo de Berlim votou, em um referendo, contra os planos de construção da administração pública no espaço do antigo aeroporto Tempelhof e em favor da sua preservação como espaço livre de uso público. $\mathrm{O}$ exame aproximado desse caso mostra um processo pouco linear, caracterizado pelo conflito entre práticas espaciais auto-organizadas (propostas por moradores urbanos) e práticas do planejamento institucional (propostas pelo Departamento de Desenvolvimento Urbano do Senado - Senatsverwaltung für Stadtentwicklung und Umwelt). Esse conflito acontece tanto de forma explícita quanto tácita, evidenciando duas lógicas diferentes de desenvolvimento urbano: uma delas tem como centro demandas e propostas coletivas de diferentes grupos de moradores; a outra é voltada para os interesses de grupos dominantes e para a manutenção da valorização fundiária e imobiliária. Não se trata, aqui, de dicotomizar uma coisa e outra, mas de analisar uma situação que é repleta de zonas cinzentas e de contradições, cuja compreensão é relevante para discutir as ambivalências e os desafios presentes em processos de auto-organização e suas práticas espaciais. ${ }^{4}$

Figura 1: Vista aérea do campo do Tempelhof. À direita, encontra-se o distrito de Neukölln, onde se iniciou a mobilização contra o desenvolvimento do espaço
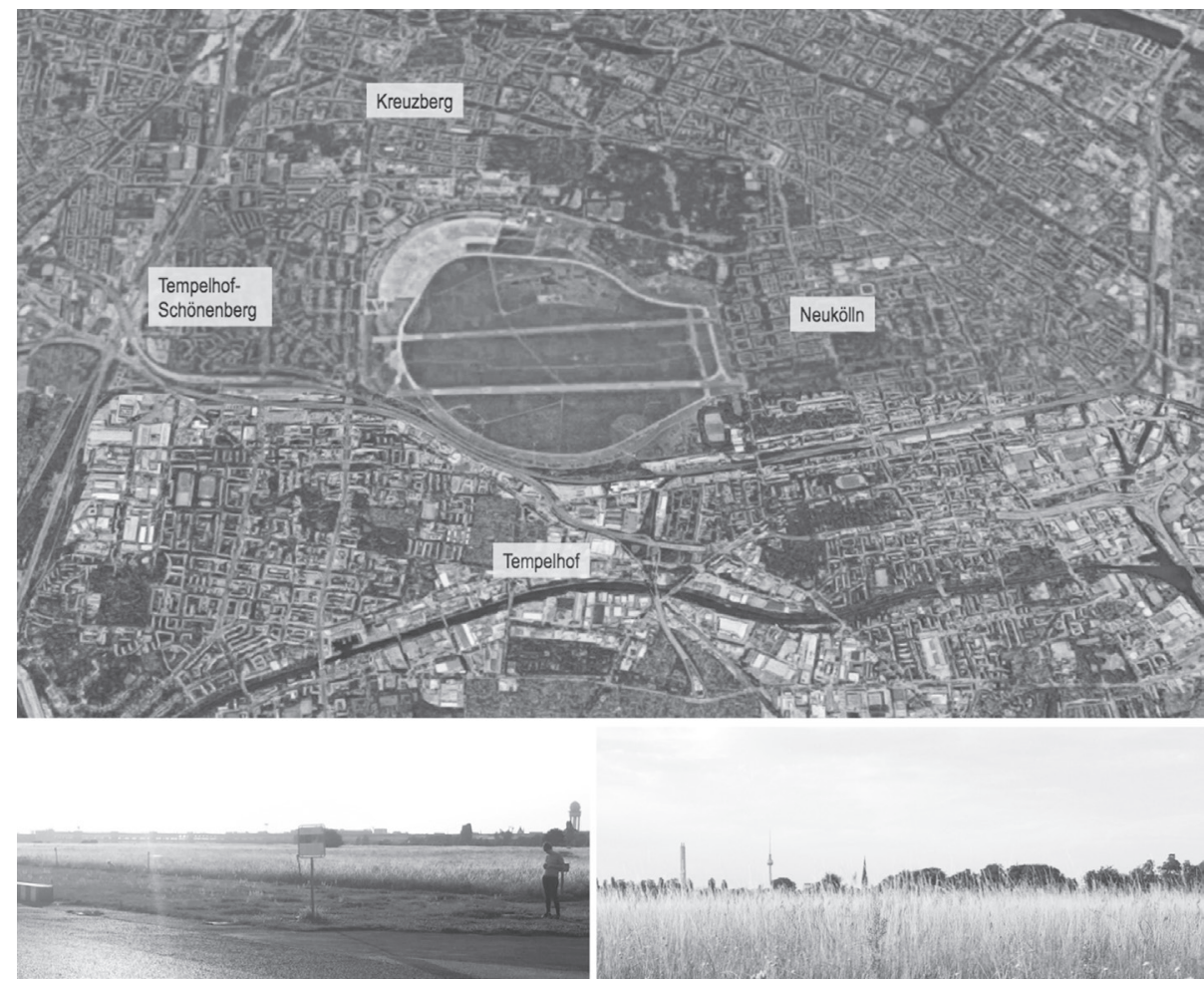

Fonte: Google Maps e arquivo pessoal da autora, 2015. 
Localizado próximo ao centro de Berlim, entre os distritos de Kreuzberg, Neukölln e Tempelhof, o espaço livre tem aproximadamente 4 milhóes de metros quadrados, o qual já era objeto de disputa antes mesmo da decisão do encerramento das atividades do aeroporto em 2008. Em 2010, o espaço foi reaberto como parque público, e, desde entáo, é intensamente utilizado pelos moradores da cidade para atividades esportivas e também para outros tipos de lazer e ócio.

A disputa pelo espaço do Tempelhof acontece em meio a uma "nova onda de disputas na política urbana” e de resistência popular contra processos de renovação urbana em distritos centrais de Berlim, como Friedrichshain, Kreuzberg e Neulkölln (HOLM; KUHN, 2011, tradução da autora). Trata-se de uma resistência contra um conjunto de problemas, como a atuaçáo de investidores da indústria da construçáo na capitalização dos espaços remanescentes nesses distritos centrais e o enfraquecimento das políticas públicas de habitação social, com o subsequente aumento dos aluguéis e a gentrificação de vizinhanças inteiras. Nesse contexto, práticas auto-organizadas, como protestos e apropriaçóes coletivas de espaços, questionam políticas urbanas neoliberais e processos de valorização de vizinhanças econômica e politicamente vulneráveis. Esses processos, que se iniciam depois da queda do muro de Berlim em 1989, são intensificados nos anos 1990 e 2000, quando a cidade privatiza mais da metade do seu estoque público habitacional e passa a ser foco de investimento imobiliário internacional (HOLM, 2013; LEBUHN, 2015).

Como apontam alguns autores, as dinâmicas dos movimentos urbanos e dos procedimentos participativos institucionais são historicamente entrelaçadas em Berlim. De acordo com Lebuhn (2015, p. 3, tradução da autora), “[...] muitos dos instrumentos participativos que podemos identificar hoje foram desenvolvidos ao longo dos anos 1990 e 2000. Mas suas raízes estão nas lutas urbanas da nova esquerda durante os anos 1960 e 1970 (MAYER, 2010)". Ao mesmo tempo que os ativismos e movimentos sociais urbanos têm uma relevância histórica no desenvolvimento da cidade e de suas políticas urbanas - como é o caso do movimento squatter nos anos 1970 e 1980 -, eles enfrentam o risco de anulamento por meio da burocratização e formalização por parte do Estado. A partir dos anos 1980, já no contexto de reestruturação neoliberal, eles passam a lidar com o risco da assimilação conveniente de suas práticas vicinais de ajuda mútua (KATZ; MAYER, 1985). Atualmente, os ativismos e movimentos de Berlim se deparam com o risco de "serem cooptados ou discursivamente mobilizados como uma adição colorida à imagem comercializada de 'cidade criativa"” (NOVY; COLOMB, 2013, p. 183, tradução da autora).

Nesse sentido, a imbricação entre movimentos sociais e práticas de planejamento institucional não implica necessariamente um maior poder de decisão e de ação dos moradores urbanos na produção do espaço. Mesmo num contexto de planejamento mais sólido e de relaçóes instituídas entre administração pública e sociedade civil, as práticas espaciais institucionais se estruturam a partir da relação entre interesse econômico e poder político, fazendo com que interesses privados prevaleçam sobre interesses coletivos, o que provoca, por conseguinte, a atuação questionadora de diferentes grupos de moradores.

O caso do campo do Tempelhof evidencia os pontos de contato e as divergências entre lógicas distintas de produção espacial. Com o objetivo de discutir o potencial político, os desafios e as ambivalências do processo de decisão e das práticas auto-organizadas, são postos em relevo, na análise a seguir, três momentos: a mobilização 
5 Schillerkiez é a vizinhança em torno da Schillerpromenade, rua localizada no distrito de Neukölln. 0 termo Kiez se refere à porção urbana reconhecida pelos moradores como sua vizinhança.

60 convite para a ocupação do Tempelhof em 2009 está disponível em: <http://tempelhof. blogsport.de/images/ flyer_rck_en.jpg>. Acesso em: 15 abr. 2016; e um vídeo mostrando alguns dos momentos da tentativa de ocupação e da violência da repressão policial pode ser visto em: <https://www. youtube.com/watch?v=v4SEp4X8cl>. Acesso em: 15 abr. 2016. pela abertura do campo do Tempelhof (2008); a abertura do parque e o processo de planejamento combinado com usos temporários (2010-2011); a contraproposta da iniciativa Tempelhofer Feld 100\% e a produçâo coletiva dos jardins comunitários ao longo do tempo (2011-2016).

\section{A MOBILIZAÇÃo dOS MORADORES PELA ABERTURA DO CAMPO DO TEMPELHOF (2008)}

A discussão sobre os planos de construção e de uso do campo do Tempelhof, que já acontecia há alguns anos por parte do Departamento de Desenvolvimento Urbano, intensifica-se com o seu fechamento em 2008. As possibilidades de desenvolvimento da área são vistas como oportunidades para atrair investidores e propiciar atividades lucrativas no contexto da indústria imobiliária (ROSKAMM, 2014). Antes mesmo do fechamento, já eram discutidos planos para a criação de "milhares de novas moradias e escritórios" na área por meio da construção de novos quarteirôes nas bordas do campo e da reestruturação das vizinhanças imediatas (SENATSVERWALTUNG FÜR STADTENTWICKLUNG UND UMWELT, 2008, tradução da autora). Uma das áreas afetadas por esses planos é a Schillerkiez ${ }^{5}$, vizinhança economicamente vulnerável e politicamente organizada contra processos de valorização imobiliária e fundiária.

Em paralelo aos planos oficiais, surgem iniciativas que questionam radicalmente essas propostas de construção. A iniciativa Tempelhof für Alle (Tempelhof para Todos), voltada para combater o processo de gentrificação na Schillerkiez, defende o uso público e não comercial da área. Uma outra frente, a Squat Tempelhof (Ocupação Tempelhof), inicia uma campanha convidando toda a população de Berlim para uma ocupação em massa da área, em junho de 2009. Fazendo referência à cultura de ocupação de espaços vagos em Berlim, a chamada no website e nos panfletos traz como título a pergunta: "Você já ocupou um aeroporto?". O texto afirma que os moradores querem decidir, por eles mesmos, o novo uso do espaço e que eles têm diversas ideias de uso náo comercial, as quais refletem as necessidades da comunidade local. ${ }^{6}$ No dia da ocupaçáo, centenas de moradores se reúnem no entorno do aeroporto para festejar, bloquear ruas e derrubar as grades. Apesar da tentativa ser reprimida fortemente pela polícia, em uma operação com cerca de mil policiais, a mobilização contribui para ampliar o debate sobre possíveis usos públicos do espaço sob o controle popular. Pode-se dizer que o interesse da populaçáo, evidenciado na açấo de diferentes grupos, influencia diretamente os momentos subsequentes do processo, inclusive as estratégias de planejamento institucional que são adotadas pelo Departamento de Desenvolvimento Urbano.

Em meio ao debate sobre planos oficiais de abertura do espaço e de construção em suas bordas, em outubro de 2009, o jornal crítico Die Tageszeitung (TAZ) publica uma proposta provocativa, sugerindo usar o espaço do Tempelhof como um experimento de democracia direta (ASMUTH, 2009). A provocação se dirige exatamente ao modo como a participação popular vinha sendo promovida pelo Departamento de Desenvolvimento Urbano, que era, em grande medida, consultiva e permitia apenas os usos temporários selecionados pela administração pública - como será explicado mais adiante. A matéria publicada defende, no lugar desse processo burocrático, a tomada de decisão direta e coletiva da população sobre o espaço. A crítica é direcio- 
nada especificamente à propaganda institucional de Berlim como "a capital da participação", apontando que, no final das contas, quem decide sobre a implementação ou não de certas ideias propostas pela população é a própria administração pública (ASMUTH, 2009, tradução da autora).

Figura 2: Mobilização para ocupar o aeroporto

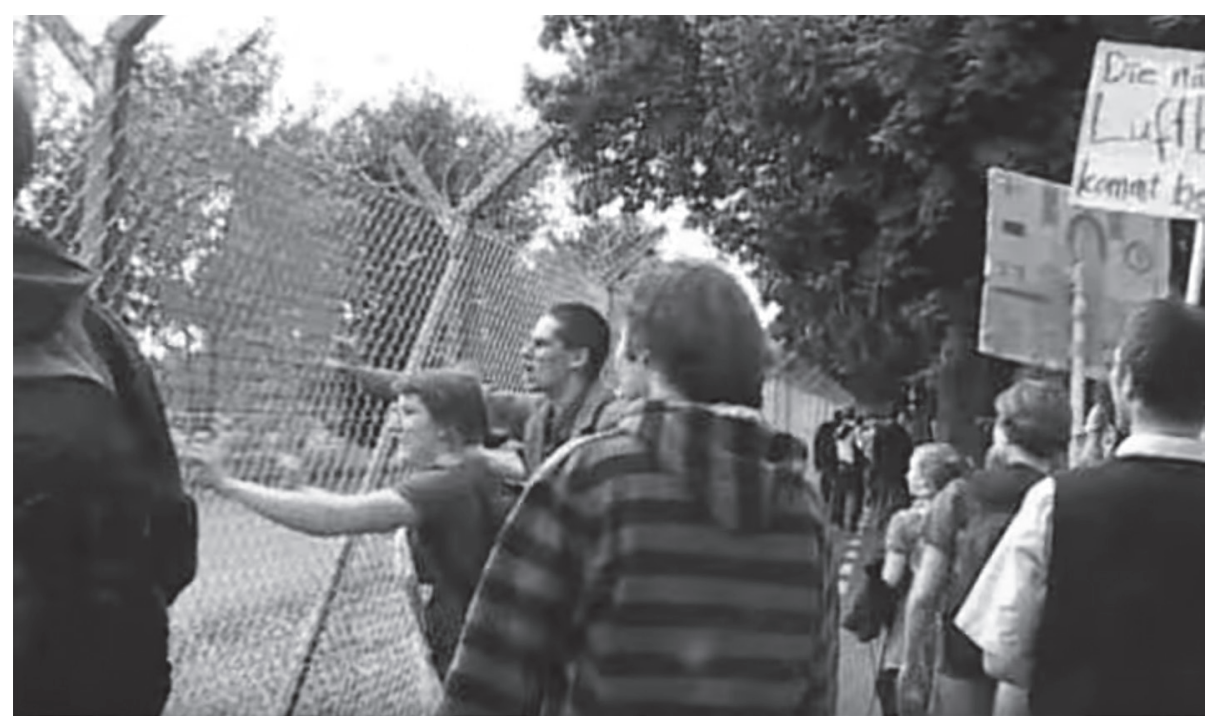

Fonte: Trecho do vídeo Aktion: Squat Tempelhof Airport, 2009 (Disponível em: <https://www. youtube.com/watch?v=v-4SEp4X8cI>. Acesso em: 15 abr. 2016).

Figura 3: Proposta do jornal TAZ

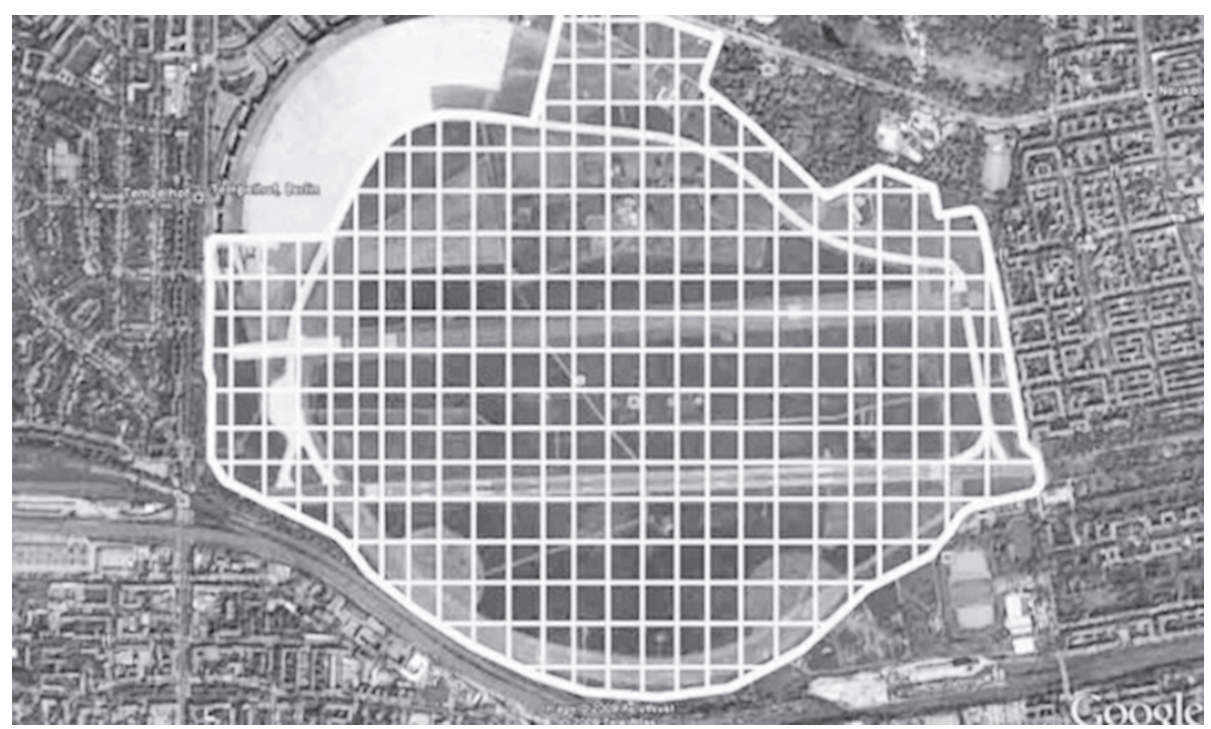

Fonte: Metrozones (Disponível em: <https://www.metrozones.info/metrozones-saloon-4-recht-aufs-tempelhofer-feld/>. Acesso em: 2 set. 2016).

A proposta do jornal apresenta uma solução para lidar com as dimensôes quase inconcebíveis da área: Ein Quadratmeter Tempelhoffür Jeden (um metro quadrado do Tempelhof para Todos), isto é, distribuir os metros quadrados do espaço em desuso (por volta de 3,5 milhóes $\mathrm{m}^{2}$ ) entre os moradores de Berlim (aproximadamente de 
3,5 milhôes de habitantes). Cada morador teria, assim, um metro quadrado, fato que demandaria uma organização coletiva das propostas, já que pouca coisa se pode fazer com apenas um metro quadrado. Um campo de futebol, por exemplo, com 7.500 metros quadrados, envolveria necessariamente 7.500 moradores negociando suas porçôes espaciais. A proposta ainda sugere o uso de instrumentos de democracia direta eletrônica, como um website contendo a vista aérea do aeroporto para que as pessoas possam escolher a localização do seu metro quadrado e conquistar adeptos para suas propostas. Segundo o autor da provocação, o processo se autorregularia como em uma Wikipedia (ASMUTH, 2009).

Essa proposta foi criticada por autores como Roskamm (2014), que aponta um suposto tom neoliberal na tentativa de se discutir a questáo por meio da noçáo de propriedade privada. Apesar da possibilidade dessa interpretação controversa, pode-se dizer que a provocação contribui para animar o debate e oferece elementos para imaginar como poderia ser, concretamente, uma produçáo coletiva e negociada do espaço ao longo do tempo. Além disso, a proposta apresenta um instrumento curioso de democracia direta para a apropriação de uma grande área por um número grande de pessoas: uma única regra (o tamanho reduzido da área de cada morador) impediria a apropriação individual do espaço e, ao mesmo tempo, propiciaria a negociação do espaço, ampliando as possibilidades de propostas coletivas, sem predeterminá-las.

\section{A ABERTURA DO PARQUE E O PROCESSO DE PLANEJAMENTO COMBINADO COM USOS TEMPORÁRIOS (2010-2011)}

Diante da pressão popular, em maio de 2010, o Departamento de Desenvolvimento Urbano decide abrir o espaço como um parque, no âmbito da proposta Tempelhofer Freiheit. A infraestrutura do parque é mínima, contando com alguns banheiros, placas de localização, pontos de informação e alguns pontos de venda de comida e bebida. De um modo geral, o espaço é mantido exatamente como um aeroporto. Segundo Roskamm (2014), é justamente o fato de o parque ser "um aeroporto sem aviōes" que atrai milhares de pessoas de todas as partes da cidade. O vento e as pistas asfaltadas propiciam uma gama de atividades que náo são possíveis em outros espaços de uso público. Ainda que exista a delimitação de áreas designadas para certas atividades, como para fazer churrasco ou soltar cachorros, o espaço se caracteriza especialmente pela indeterminação de uso devido à inexistência de um desenho de parque - com caminhos, bancos, iluminação estratégica e canteiros. $\mathrm{O}$ dia da abertura é marcado por diversos protestos - todos controlados pela polícia - de grupos anticapitalistas e contra o aumento de aluguéis nas adjacências do aeroporto (BERGT, 2010).

Como parte do plano de desenvolvimento do espaço a longo prazo, ainda em 2010, o Departamento de Desenvolvimento Urbano abre uma chamada para que diferentes grupos da sociedade proponham usos pioneiros e temporários do campo (Zwischenund Pioniernutzer). $\mathrm{O}$ texto da chamada assume que essa estratégia de planejamento tem como referência a cultura de uso temporário e espontâneo de áreas vazias pela populaçáo de Berlim. Essa narrativa busca evidenciar a predisposição da administraçáo pública em estabelecer uma cooperação entre planejamento institucional e demandas propostas pelos moradores (TEMPELHOF PROJEKT, 2010). Como resposta, diversos grupos se organizam, e de 138 propostas, 19 são selecionadas para ocupar três 
espaços nas bordas do campo - Neuköllner Nachbarschaften (vizinhança de Neukölln), Kombinierte Sport-und Kulturnutzung (uso combinado de esporte e cultura) e Wissenschaft Kultur (estudos culturais), sendo que nem todas são implementadas. Entre as principais propostas implementadas, estão os jardins comunitários localizados na borda destinada às atividades da vizinhança de Neukölln, que constituem uma das práticas analisadas nesse caso: o conjunto formado pelos jardins Allmende-Kontor, Stadtleigarten Schillerkiez e Rübezahlgarten, produzidos coletivamente por grupos de moradores da Schillerkiez e por ativistas ligados ao plantio urbano comunitário. Existem, atualmente, outros 14 projetos pioneiros no campo, entre eles, um minicampo de golfe e uma oficina de bicicletas, conduzidos também por organizaçôes registradas e sem fins lucrativos.

Figura 4: As três áreas reservadas para os usos pioneiros

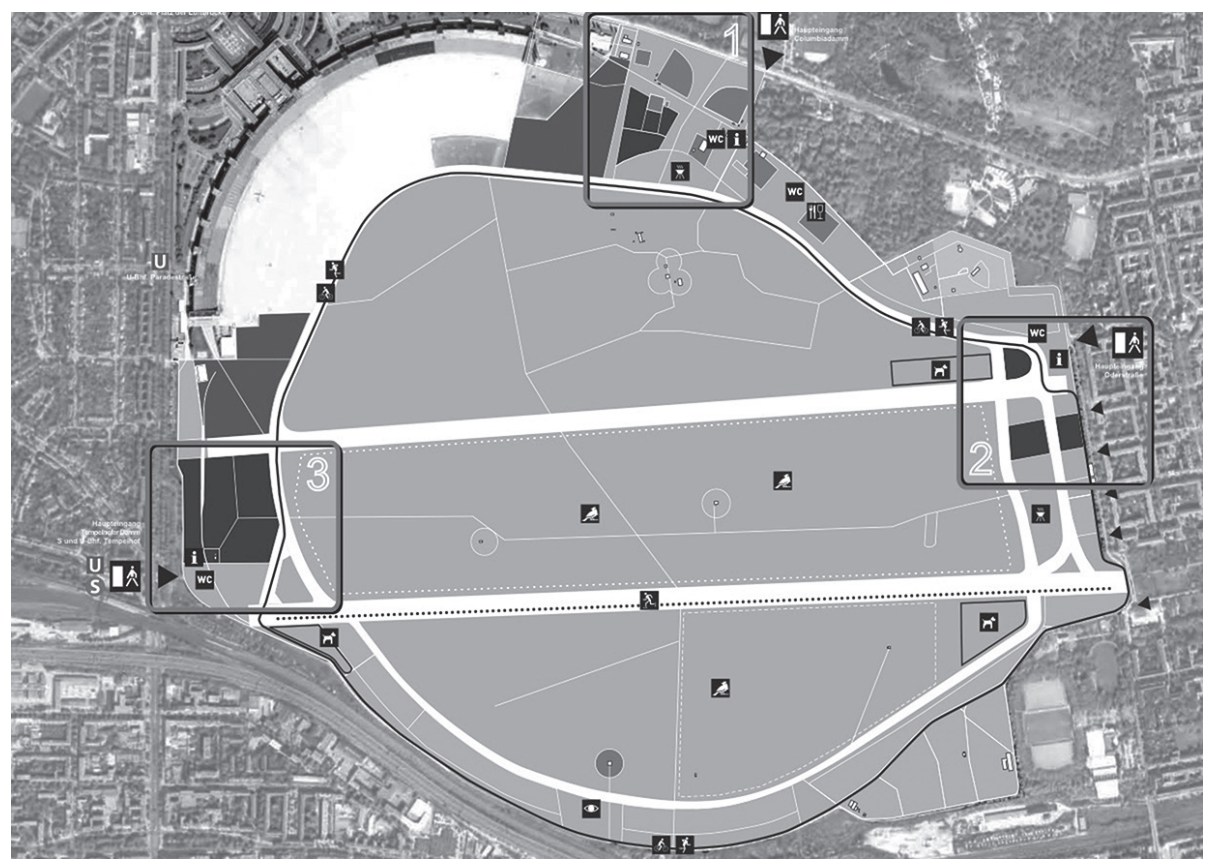

Fonte: Senatsverwaltung für Stadtentwicklung und Umwelt (2010).

A permissão inicial para a atividade de plantio comunitário seria de seis anos, mas, antes mesmo da instalaçáo dos jardins, a permissão foi reduzida para três anos. Como os grupos não têm autorização para plantar diretamente no solo - tanto pelo caráter temporário da permissão quanto por um suposto risco de contaminação do solo -, os jardins são plantados em jardineiras suspensas. Além das jardineiras, são construídos espaços de estar, com mesas, bancos e estruturas de madeira em cada núcleo de plantio. Essa área passa a ser utilizada intensamente pela população que visita o parque diariamente, sobretudo nos fins de semana. É interessante observar que a primeira impressão que se tem ao visitar esse espaço é a de que os jardins comunitários são fruto de uma ocupação totalmente espontânea. Mas essa impressão é ligeiramente distorcida por placas oficiais da administraçáo pública que, de certa maneira, explicitam que se trata de um espaço concedido e controlado por ela. 
Figura 5: Os jardins comunitários no Tempelhofer Feld
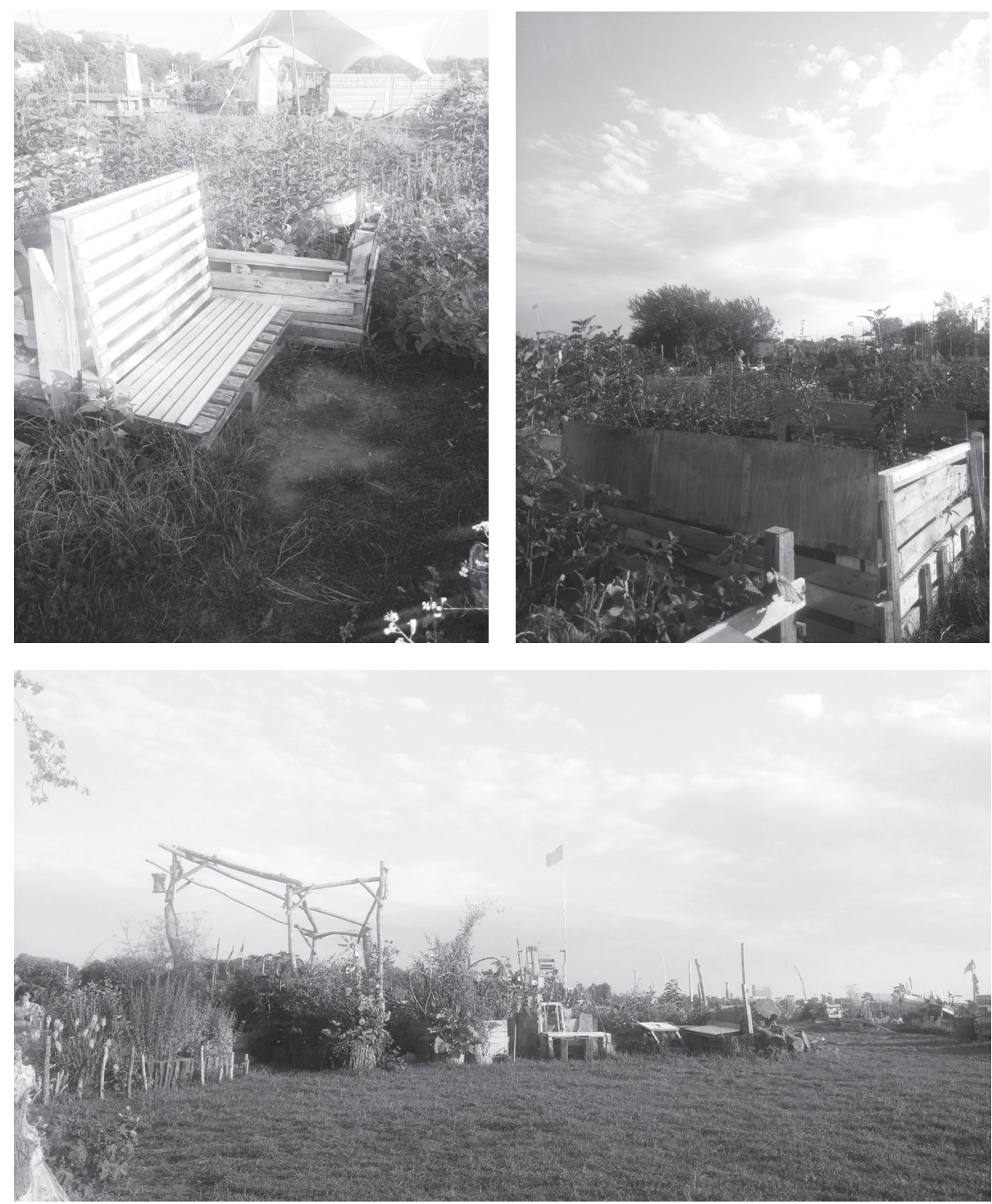

Fonte: Arquivo pessoal da autora, 2015.

Enquanto os usos pioneiros se consolidam, o Departamento de Desenvolvimento Urbano passa a trabalhar com a proposta vencedora de um dos concursos realizados: um masterplan, com construçôes nas bordas do campo e um parque no centro - nos 230 hectares restantes -, envolvendo um investimento público consideravelmente alto e a participaçáo de investidores privados. O plano prevê, além das 4.700 unidades de moradia e escritório, uma biblioteca nacional, a reestruturação das vizinhanças para conectá-las aos novos quarteiróes que serão construídos, uma estação de metrô, passarela de pedestre etc. A proposta, curiosamente, desconsidera os usos pioneiros, prevendo novas construçóes em suas áreas, o que é endossado pela administração pública em um dos documentos de apresentação do plano: "no presente, o campo do Tempelhof abriga 13 projetos nos terrenos pioneiros, cobrindo uma área de 12 a 19 hectares que são designados para construçôes futuras, permitindo apenas o seu uso limitado" (SENATSVERWALTUNG FÜR STADTENTWICKLUNG UND 
UMWELT, 2012, tradução da autora). A área ocupada pelos jardins é igualmente ignorada pelo plano, que propóe, além dos blocos de apartamentos na borda onde se localizam, um enorme monumento de pedra, como mostra a Figura 6. As novas construçóes são representadas de modo quase transparente, disfarçando o seu real impacto no campo.

Figura 6: Trecho do plano vencedor do concurso

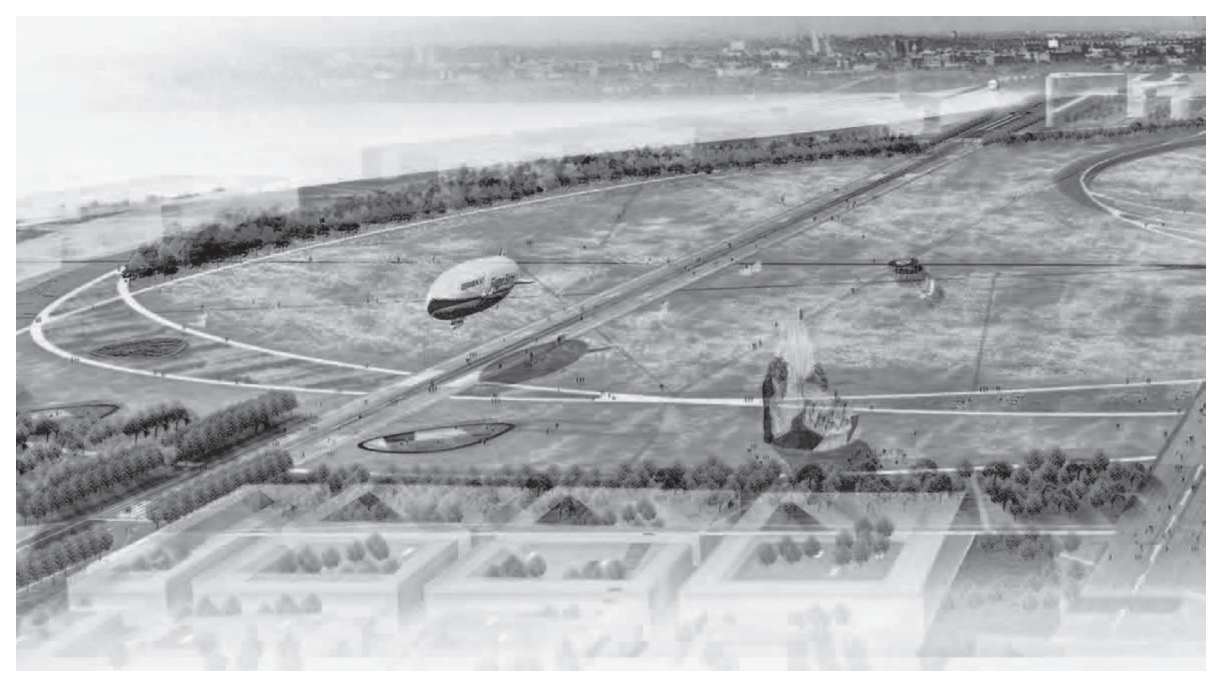

Fonte: Senatsverwaltung für Stadtentwicklung und Umwelt (2012).

Pode-se dizer que, nesse momento, o conflito entre práticas auto-organizadas e planejamento institucional, que até então acontecia de forma relativamente controlada, fica evidente, provocando uma nova onda de mobilizaçóes contra as práticas de planejamento da administração pública.

\section{A CONTRAPROPOSTA DA INICIATIVA TEMPELHOFER FELD $100 \%$ (THF 100\%) E A PRODUÇÃO COLETIVA DOS JARDINS COMUNITÁRIOS AO LONGO DO TEMPO (201 1-2016)}

Duas frentes podem ser destacadas em função da repercussão direta delas na produção do espaço do Tempelhof: uma é a iniciativa Tempelhofer Feld 100\%, que elabora uma contraproposta ao plano da administraçáo pública por meio de um referendo; e a outra é a produção e permanência dos jardins comunitários para além do limite de tempo concedido no contexto dos usos pioneiros e temporários.

A iniciativa THF 100\% é fundada na vizinhança Schillerkiez em 2011, na esteira das iniciativas já mencionadas. Diante da notícia sobre os planos de construção e com o apoio de moradores de outra parte da cidade, a iniciativa amplia a sua campanha para a realização de um referendo. Questionando o plano de construção e a falta de poder de decisáo dos moradores, é elaborada uma contraproposta por meio de uma lei que define a preservaçáo total do campo, a manutenção do seu uso público e a possibilidade de projetos comunitários. O objetivo dessa lei é impedir qualquer plano de construção e a privatização do espaço por parte da administração pública. Os argumentos da lei têm como foco principal o uso público do espaço pelos moradores da cidade, a diversidade da fauna e flora do local, a ameaça do aumento de 
aluguéis e da gentrificação das vizinhanças econômica e politicamente vulneráveis do entorno e a importância história do aeroporto (SCHALK, 2014; THF100\%, 2014). Inicialmente, a iniciativa THF 100\% não se opóe apenas ao plano apresentado pela administração pública, mas também a qualquer plano futuro que envolva a alteração do espaço visando ao lucro.

Durante a campanha em prol do referendo, a iniciativa faz um trabalho intensivo de divulgação das informaçôes que estavam em jogo, especialmente por meio de jornais - no formato popular de tabloide com textos simples, diretos e repletos de imagens -, e também através de postagens em seu website, em uma lista de e-mail, na página do Facebook e em reuniôes nas vizinhanças da cidade com a presença de grupos locais organizados contra o aumento de aluguéis e outras questóes do espaço urbano. Esse trabalho contribui para incrementar o nível do debate entre os moradores, fazendo com que o assunto passe a ser veiculado nos principais meios de comunicação da cidade. A Figura 7 mostra um dos jornais distribuídos pela iniciativa. À esquerda, o masterplan é apresentado sob o título "retorno para poucos", com detalhes sobre o investimento público que seria utilizado. À direita, é explicitada a proposta da iniciativa, sob o título "cidade para todos", mostrando as vantagens de se manter o espaço preservado e de se utilizar o investimento previsto para a construção do masterplan em outras áreas, como habitação social e educação. O objetivo é explicar as opçóes que as pessoas teriam na cédula no dia do referendo, do que cada uma delas trata e seus argumentos.

Figura 7: Folha interna do jornal distribuído antes do referendo, apresentando as duas propostas em disputa

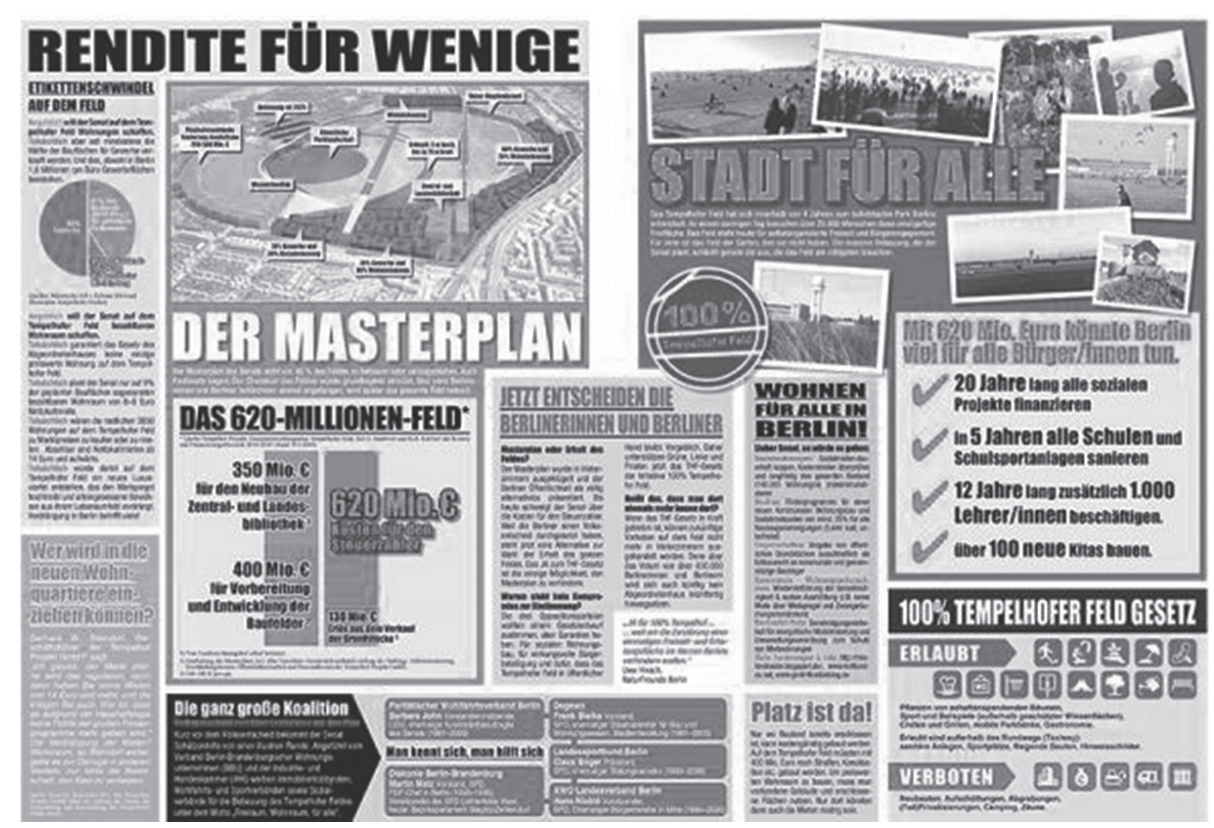

Fonte: Website da iniciativa THF 100\% (kampagnenzeitung) (THF100\%, 2014).

Em maio de 2014, depois de passar pelas etapas burocráticas exigidas para a realizaçáo do referendo, $65 \%$ dos votos decide pela manutenção da área como um espaço livre e público, interrompendo os planos de construção. A lei traz dois aspectos 
importantes: a preservação total do campo e um processo de planejamento participativo. Usando um instrumento extremamente regulado e formal, a iniciativa cria condiçóes para que o debate sobre o poder de decisão dos moradores sobre os espaços da cidade aconteça amplamente e de modo informado, extrapolando o momento da votação. Para Lebuhn (2015, p. 7, tradução da autora), é, ironicamente, por meio do "canal mais pré-formatado" de participação que diferentes grupos encontram um objetivo comum e avançam na discussão da questão do controle democrático dos recursos urbanos.

Desde então, o Departamento de Desenvolvimento Urbano vem promovendo um processo participativo para a formulação do Plano de Desenvolvimento e Manutenção (Entwicklungs- und Pflegeplan, o EPP) do campo do Tempelhof. Apesar da considerável quantidade de recurso utilizada nesse processo, poucos participam, havendo, em média, 50 pessoas por reunião. Trata-se de um número pequeno, especialmente se comparado à mobilização externa e anterior a esse momento institucionalizado. Além das inúmeras reuniôes presenciais, as discussões acontecem por meio de uma plataforma no website, na qual as pessoas podem fazer sugestóes para o plano. Segundo uma integrante da iniciativa, ao contrário do processo por eles proposto, o plano institucional parece, propositalmente, complicado e não envolve a tomada de decisão, apenas o apontamento de possibilidades e diretrizes. A participação pelo website é apontada como um problema por não permitir a difusão concreta de responsabilidades e o encaminhamento das propostas, já que nem todo mundo se identifica ao participar da plataforma, não ficando claro quem é a pessoa que está sugerindo determinada ideia. ${ }^{7}$

Os jardins comunitários são, além da iniciativa THF 100\%, uma das frentes que atuam diretamente na produção do espaço. Como já mencionado, a sua produção acontece a partir da abertura da administração pública a propostas da população em um certo momento do processo de planejamento anterior ao referendo. Os grupos responsáveis pela produção dos jardins Allmende-Kontor, Stadtleigarten Schillerkiez e Rübezahlgarten conseguem se organizar o suficiente para garantir a sua permanência para além dos três anos que estavam previstos no contrato, o que também acaba contribuindo para a campanha do referendo. Os colaboradores atuam por meio de um arranjo auto-organizado de produção e de manutenção da área, que é repleta de jardineiras e de espaços de uso público. ${ }^{8}$ Além de enfrentarem um processo burocrático para renovar, anualmente, a permissão, os integrantes pagam uma taxa para a administraçấo pública - taxa que já tentaram eliminar diversas vezes, sem sucesso até o momento, sob a justificativa de que atuam na manutençâo de uma área que é uma das mais usadas no Tempelhofer Feld. Com a nova situação do espaço após o resultado do referendo, os jardins se estabelecem, superando o caráter anterior de uso temporário. Apesar da força política conquistada ao longo do tempo, seus integrantes são críticos em relação às limitações que enfrentam, e a dependência de renovação anual do acordo limita seu pleno desenvolvimento.?
7 Informações obtidas por meio de observação direta e entrevistas.

9 Informações obtidas por meio de entrevistas. 


\section{AMBIVALÊNCIAS DAS PRÁTICAS ESPACIAIS AUTO-ORGANIZADAS NO CAMPO DO TEMPELHOF}

O processo de decisão sobre o destino do campo do Tempelhof, semelhante a outros processos que envolvem espaços em disputa em grandes cidades, evidencia o conflito entre práticas espaciais auto-organizadas e práticas do planejamento urbano institucional. Em alguns momentos, esse conflito acontece de modo tácito, com uma certa conciliação entre planejamento e práticas auto-organizadas. Em outros, ele é explícito, provocando respostas mais diretas por parte dos moradores e ativistas.

Retomando a noção de um processo de democratização radical da produção do espaço e a tentativa de identificar as ambiguidades, possibilidades e desafios das práticas auto-organizadas compreendidas como catalisadoras desse processo, a seguir são discutidos alguns aspectos à luz dos pressupostos apresentados inicialmente.

\section{PARTICIPAÇÃo INSTITUCIONALIZADA COMO ENTRAVE PARA O DESENVOLVIMENTO DE PRÁTICAS AUTO-ORGANIZADAS}

As práticas auto-organizadas conseguem driblar, ora mais, ora menos, os impedimentos que surgem ao longo do processo examinado, adotando diferentes estratégias e instrumentos que alteram as condiçóes para a discussão coletiva e para a tomada de decisão direta dos moradores urbanos. Por um lado, as práticas avançam na divulgação de informaçóes que são, em grande medida, acessadas por especialistas e na criaçáo de espaços políticos para o debate e elaboraçáo de contrapropostas. Por outro, elas enfrentam o risco de esgotamento e de enquadramento burocrático quando adentram canais de participação.

Pode-se observar, ao longo desse processo de decisão, uma disputa entre duas lógicas contrárias de produçáo espacial. A lógica auto-organizada tem a possibilidade de permitir alternativas aos princípios da lógica institucional, entre eles, a coordenação por parte de um especialista, a separação das etapas de projeto, construção e uso, assim como a existência de um plano, o qual serve à inserção da produção espacial numa ordem econômica e institucional que viabiliza orçamentos, alocação de recursos e aprovaçóes legais (BALTAZAR; KAPP, 2006). O formato do processo de planejamento institucional posto em prática, inicialmente, no campo do Tempelhof propicia a abertura para usos pioneiros e temporários, mesclando essas duas lógicas de produção espacial até certo ponto e permitindo que a etapa de uso se misture à de planejamento. Alguns argumentam que esse formato se diferencia dos formatos convencionais de participação e que a mobilização de usos temporários, em paralelo ao planejamento a longo prazo, é uma tentativa de sincronizar essas duas lógicas (MACKRODT; HELBRECHT, 2013; SCHALK, 2014). No entanto, ainda que seja um experimento de planejamento interessante e que haja ganhos por parte dos grupos auto-organizados - como os produtores dos jardins -, esse processo se mostra frágil quando a burocracia institucional prevalece e estabelece um limite de tempo para os usos pioneiros, não os considerando como parte da produção efetiva do espaço a longo prazo. Isso significa que, nesse caso, o planejamento aberto à ação coletiva de diferentes grupos é uma experimentação temporária, em que a produção coletiva 
é simbólica, servindo, no máximo, para inspirar um projeto que será produzido e executado, posteriormente, de modo convencional. A fragilidade desse processo fica ainda mais evidente quando os usos temporários não constam como parte do plano oficial divulgado pela administração pública.

Trata-se, por fim, de um processo que náo altera uma das principais características da lógica institucional hegemônica: a concentração de poder de decisão nas mãos de técnicos contratados pela administração pública para coordenar um processo de produção espacial que é, em grande medida, atrelado aos interesses de grupos dominantes.

A incorporação das práticas auto-organizadas em processos de planejamento participativos não necessariamente significa que os agentes dessas práticas serão considerados como tomadores de decisão. Observando o desenvolvimento da proposta dos usos temporários e, principalmente, o processo participativo convencional adotado após o referendo, não causa nenhum espanto o fato de que alguns dos moradores entrevistados afirmem que é muito comum experimentar processos em que a participação deles é impedida pela participação institucionalizada. ${ }^{10} \mathrm{~A}$ discussão sobre a postura estadocrítica, proposta por Souza (2012), mostra-se útil para a análise dessa situação. Se, por um lado, a utilizaçáo de brechas no contexto do planejamento participativo é oportuna, por outro, é importante que as práticas se auto-organizem para além disso, adotando a luta institucional como tática conjugada e subordinada à ação direta (SOUZA, 2006a; 2006b; 2012). Ou seja, trata-se de uma complementaridade que envolve a mobilização de instrumentos formais e de canais participativos sem o abandono da auto-organização de estruturas próprias de discussão e de ação.

\section{O POTENCIAL E OS LIMITES DA CONTRAPROPOSTA}

Alguns críticos da lei proposta pela iniciativa THF 100\% a consideram conservadora por impedir alteraçóes no espaço. Um contra-argumento a essa consideração seria afirmar que, diante do contexto de valorização do espaço urbano em Berlim, manter a área como está - favorecendo o seu uso coletivo e preservando seus atributos naturais e históricos - é uma proposta transformadora. Viabilizada por um instrumento bastante burocrático, a proposta que interdita a realizaçáo de empreendimentos que beneficiam agentes de interesse privado constitui uma força contrária à produção hegemônica do espaço. É importante apontar ainda que, desde 2007, a administração pública vinha promovendo processos de participação e consulta à população sobre os planos para o espaço, sem que o pressuposto de construção nas suas bordas pudesse ser questionado. $\mathrm{O}$ uso do referendo foi uma forma de desconstruir esse pressuposto, que parecia incontestável, por meio da participação institucionalizada no planejamento. O potencial da contraproposta também está no seu caráter de antiplanejamento e de antiprojeto, ao pleitear a preservação de um espaço público sem desenho de parque convencional e sem pretender determinar esse desenho no futuro. Apesar de a lei não explicitar como poderia ser o processo de produção espacial, seu caráter indeterminado pode ampliar possibilidades de produção consonantes com o tipo de imaginação das primeiras propostas elaboradas, como a ocupação popular do espaço e a negociação coletiva dos usos.

O debate levantado ao longo do processo extrapola a questão do campo do Tempelhof, fortalecendo a discussão sobre a valorização de porçóes urbanas no
10 Informações obtidas por meio de observação direta e entrevistas. 
11 Disponível em: <https:// mietenvolksentscheidberlin. de/>. Acesso em: 15 abr. 2016.

12 Entre a submissão do artigo e a sua revisão final, um acontecimento reaquece o debate sobre o campo do Tempelhof e o referendo: a administração pública de Berlim anuncia, no final de 2015, que a lei aprovada via referendo deve ser alterada para viabilizar a construção de abrigos temporários para os refugiados recémchegados à cidade. Sem que outras possibilidades de acomodação fossem consideradas, a alteração da lei é aprovada pelo órgão legislativo, apesar dos protestos da iniciativa THF 100\% e do Conselho de Refugiados de Berlim (Flüchtlingsrat Berlin) - que, além de se oporem à alteração de uma decisão tomada via democracia direta, são contrários ao isolamento das pessoas recém-chegadas em abrigos com condições de vida questionáveis, defendendo alternativas dignas de moradia social que favoreçam a integração delas e evitem a sua estigmatização. Diante disso, a iniciativa THF 100\% se engaja em 2016 numa nova campanha: um referendo para alterar as regras que dizem respeito ao referendo na Constituição, cujo objetivo é garantir maior controle por parte da população sobre o instrumento e seus resultados. entorno do aeroporto, o aumento dos aluguéis e a situaçáo da política de habitação social da cidade. Isso se intensifica, posteriormente, com a organização da campanha para um novo referendo, voltada para a questão dos aluguéis (o Mietenvolksentscheid $)^{11}$. Nesse caso, é possível notar que existe um processo pedagógico das práticas auto-organizadas por meio do compartilhamento de informaçôes sobre seus métodos organizacionais, sobre suas estruturas, táticas e estratégias.

Um dos limites da proposta da iniciativa, o qual se deve ao próprio formato do referendo, é o foco no produto, não no processo de produção espacial em curto, médio e longo prazo. Além disso, a falta de uma estratégia de ocupação e de produção direta e material do espaço, paralela à estratégia legislativa e para além dos canais participativos, deixa o espaço vulnerável a possíveis alteraçóes da lei no futuro. ${ }^{12}$

\section{PRÁtICAS AUTO-ORganizAdAS NO CONTEXTO DO NEOLIBERALISMO}

Ao mesmo tempo que apresentam alternativas e propiciam o debate sobre a atuação de diferentes moradores urbanos na produção do espaço, a auto-organização dos diferentes coletivos no caso do Tempelhof pode ser incorporada a processos de valorização fundiária e imobiliária. Isso pode realmente acontecer, ainda que as práticas auto-organizadas tenham se desenvolvido a partir do questionamento desses processos por parte dos moradores da Schillerkiez e apoiadores. Apesar de Berlim ter parques e áreas verdes de acesso público em toda a sua extensão, o campo do Tempelhof pode servir de elemento que reforça a valorizaçấo do entorno, favorecendo processos de gentrificação. Práticas que emergem inicialmente da mobilização contra a valorização e gentrificação de uma vizinhança antes desvalorizada, por estar próxima a um aeroporto, assim como a própria movimentação pelo referendo e o seu resultado, podem acabar, involuntariamente, contribuindo para incrementar o interesse imobiliário e a valorização da área.

Experiências como a produção de jardins comunitários são aceitas e apoiadas institucionalmente na mesma medida em que não interferem de maneira direta na estrutura de poder da produção do espaço. As suas práticas podem ainda ser incorporadas por estratégias neoliberais que visam a "[...] envolver a sociedade civil na governança urbana [...] passando responsabilidades do Estado para a sociedade" (ROSOL, 2011, p. 240, tradução da autora), sem que isso signifique o compartilhamento do poder de decisão e de ação sobre o espaço urbano. Desenvolvendo uma crítica sobre essa mesma ambivalência, Lebuhn (2011, p. 61, tradução da autora) aponta para a capacidade de o neoliberalismo "[...] ocupar e instrumentalizar o tempo e a energia criativa que os cidadáos colocam em projetos coletivos" e para o fato de que jardins comunitários também podem favorecer o aumento dos valores de propriedade e processos de gentrificação em uma determinada área. Muitas organizaçôes que atuam em disputas espaciais em Berlim podem ser contraditoriamente incorporadas nesse contexto neoliberal pela máquina institucional de propaganda da administração pública. Essa apropriaçáo faz com que práticas auto-organizadas percam força política e sejam incorporadas a processos que, no final das contas, contribuem para manter as situaçôes de desigualdade econômica e política contra as quais lutavam. 


\section{CONCLUSÃO}

A análise crítica de práticas auto-organizadas em situaçôes de disputa por poder de decisão sobre uma porção urbana evidencia as suas ambivalências e os desafios para que atuem na ampliação das condiçôes de atuação coletiva dos moradores urbanos. Os elementos aqui discutidos buscam servir à reflexão das práticas de planejamento - principalmente as que se pretendem abertas e participativas - e à imaginaçáo de estruturas e instrumentos que possam vir a ser criados no âmbito de processos de auto -organização e que contribuam para expandir o campo de atuação dos moradores urbanos na definição da cidade.

Os processos de auto-organização e suas práticas espaciais contribuem para tornar a prática da discussão, da tomada de decisão e da açáo coletiva como parte do cotidiano dos moradores urbanos. O caso apresentado mostra que essa tarefa não é simples e que as práticas são caracterizadas por limites e contradiçóes no seu desenvolvimento. Ou seja, os desafios para a construção da autonomia coletiva e da autogestão estão tanto na relação dessas práticas com o planejamento institucional quanto nos próprios processos de auto-organização. Como Lefebvre (2009, p. 134, tradução da autora) aponta, a prática da autogestão é especialmente importante dado seu caráter crítico e dialético, sendo que ela "[...] nunca se apresenta com a claridade e obviedade de uma operação técnica e puramente racional”, mas como uma luta.

A possibilidade de conexáo entre a experiência cotidiana da cidade e a definição coletiva do seu desenvolvimento material depende da criação e da manutenção auto-organizada de arranjos alternativos abertos à açáo direta de diferentes grupos. Retomando a perspectiva estadocrítica (SOUZA, 2006b; 2012, p. 17), se, por um lado, esse processo ocorre independentemente do aparato institucional, por outro, ele dialoga, interfere nesse aparato e explicita as suas contradiçóes, podendo provocar transformaçóes na direção do reconhecimento e da inclusão de coletivos de moradores como agentes com poder de decisão sobre a produção do espaço. Esse parece ser um passo necessário para a construção de cidades justas e democráticas.

\section{REFERÊNCIAS}

ASMUTH, G. Ein Quadratmeter Tempelhof für jeden. Taz, Berlim, 29 out. 2009. Disponível em: <http://www.taz.de/!5153500/>. Acesso em: 15 set. 2015.

BALTAZAR, A. P.; KAPP, S. Por uma Arquitetura não planejada: o arquiteto como designer de interfaces e o usuário como produtor de espaços. Impulso, Piracicaba, v. 17, n. 44, p. 93-103, 2006. Disponível em: <http://www.mom.arq.ufmg.br/mom/05_biblioteca/ acervo/baltazar_por_uma.pdf>. Acesso em: 15 abr. 2016.

BERGT, S. Nicht alle sind willkommen. Taz, Berlim, 8 maio 2010. Disponível em: <http:// www.taz.de/!5143022/>. Acesso em: 15 set. 2015.

HARVEY, D. Rebel Cities: From the Right to the City to the Urban Revolution. Verso: London and New York, 2012.

HOLM, A. Berlin's Gentrification Mainstream. In: ; BERNT, M. (Org.). The Berlin

Reader. A Compendium on Urban Change and Activism. Bielefeld: Transcript, 2013. p. 171-187

; KUHN, A. Squatting and urban renewal: The interaction of squatter move-

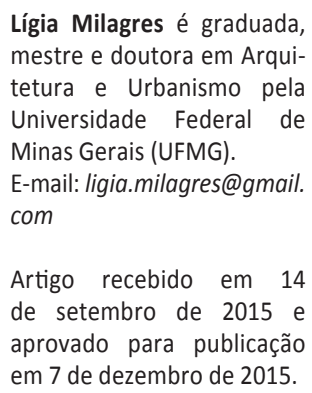

Lígia Milagres é graduada, mestre e doutora em Arquitetura e Urbanismo pela Universidade Federal de Minas Gerais (UFMG).

E-mail: ligia.milagres@gmail. com

Artigo recebido em 14 de setembro de 2015 e aprovado para publicação em 7 de dezembro de 2015. 
ments and strategies of urban restructuring in Berlin. International Journal of Urban and Regional Research, v. 35, n. 3, p. 644- 658, maio 2011. http://dx.doi. org/10.1111/j.1468-2427.2010.001009.x

KAPP, S. et al. Arquitetos nas favelas: três críticas e uma proposta de atuação. In: CONGRESSO BRASILEIRO HABITAÇÃO SOCIAL, 4., 2012, Florianópolis; CONGRESSO IBERO-AMERICANO HABITAÇÃO SOCIAL, 3., 2012, Florianópolis. Anais... Florianópolis: UFSC, 2012. Disponível em: <http://www.mom.arq. ufmg.br/mom/arq_interface/2a_aula/MOM_CTHab_2012.pdf>. Acesso em: 15 abr. 2016.

KATZ, S.; MAYER, M. Gimme shelter: self-help housing struggles within and against the state in New York City and West Berlin. International Journal of Urban and Regional Research, v. 9, n. 1, p. 15-46, mar. 1985. http://dx.doi.org/10.1111/j.1468-2427.1985. tb00419.x

LEBUHN, H. Community Gardening and Grassroots Politics in the Neoliberal City. In: FRANCESCHINI, A.; MILICEVIC, M. (Ed.). Beneath the Pavement. A Garden. Loughborough: Loughborough University: Radar, 2011. p. 52-62.

Urban Social Movements between Protest and Participation. In: RC21 INTERNATIONAL CONFERENCE, 2015, Urbino. RC21 International Conference on "The Ideal City: between myth and reality. Representations, policies, contradictions and challenges for tomorrow's urban life. Urbino: RC21, 2015. Disponível em: <http://www.rc21. org/en/wp-content/uploads/2014/12/E10.1-Lebuhn.pdf>. Acesso em: 15 abr. 2016.

LEFEBVRE, H. The survival of capitalism. Reproduction of the relations of production. Londres: Allison and Busby Limited, 1976.

. State, Space, World - selected essays. Minneapolis: University of Minnesota Press, 2009.

MACKRODT, U.; HELBRECHT, I. Performative Bürgerbeteiligung als neue Form kooperativer Freiraumplanung. disP - The Planning Review, v. 49, n. 4, p. 14-24, abr. 2013. http://dx.doi.org/10.1080/02513625.2013.892782

NOVY, J.; COLOMB, C.; Struggling for the right to the (creative) city in Berlin and Hamburg. New urban social movements, new 'spaces of hope'? International Journal of Urban and Regional Research, v. 37, n. 5, p. 1816-1838, set. 2013. http://dx.doi. org/10.1111/j.1468-2427.2012.01115.x

PURCELL, M. Seeking Democracy. Society and Space - Environment and Planning, 2013. Disponível em: <http://societyandspace.com/material/discussion-forum/forum-onturkey/purcell/>. Acesso em: 15 set. 2015.

ROSKAMM, N. 4.000.000 Square Meters Public Space and a short Walk with Lefebvre and Laclau. In: DEGROS, A.; KNIERBEIN, S.; MADANIPOUR, A. (Ed.). Public Space and the Challenges of Urban Transformation in Europe. New York, London: Routledge, 2014. p. 63-77.

ROSOL, M. Community volunteering as a neo-liberal strategy? The case of green space production in Berlin. Antipode, v. 44, n. 1, p. 239-257, 2011. http://dx.doi. org/10.1111/j.1467-8330.2011.00861.x

SCHALK, M. Utopian desires and institutional change. In: BRADLEY, K.; HEDRÉN, J. (Ed.). Green Utopianism: perspectives, politics and micro-practices. New York: Routledge, 2014. p. 131-149.

SENATSVERWALTUNG FÜR STADTENWICKLUNG UND UMWELT BERLIN. Zukunft - Tempelhofer Feld, 2008. Disponível em: <http://www.stadtentwicklung. berlin.de/aktuell/pressebox/archiv_volltext.shtml?arch_0803/nachricht2972.html>. Acesso em: 25 set. 2015.

Tempelhof Parkland - invitation to tender, 2010. Disponível em: <http://www.stad- 
tentwicklung.berlin.de/aktuell/wettbewerbe/ergebnisse/2010/parklandschaft_tempelhof/ausschreibungstext_engl.pdf>. Acesso em: 15 maio 2016.

. Tempelhof Parkland - the concept, 2012. Disponível em: <http://www.stadtentwicklung.berlin.de/aktuell/wettbewerbe/ergebnisse/2011/parklandschaft_thf_verhandlungsverfahren/download/thf_wettbewerb_flyer_en.pdf>. Acesso em: 15 jun. 2016.

SOUZA, M. L. A prisão e a ágora: reflexóes em torno da democratização do planejamento e da gestão das cidades. Rio de Janeiro: Bertrand Brasil, 2006a.

. Together with the state, despite the state, against the state - social movements as 'critical urban planning' agents'. City, v. 10, n. 3, p. 327-342, dez. 2006 b.

. Mudar a cidade: uma introduçáo crítica ao planejamento e à gestáo urbanos. Rio de Janeiro: Bertrand Brasil, 2010.

. Ação direta e luta institucional: complementaridade ou antítese? (1 $1^{\mathrm{a}}$ e $2^{\text {a }}$ partes). Passa Palavra, Florianópolis, abr. 2012.

TEMPELHOF PROJEKT. Zwischen- und Pioniernutzer der Tempelhofer Freiheit. 2010. Disponível em: <http://www.thf-berlin.de/fileadmin/user_upload/Mitgestalten/ Pioniere_der_Tempelhofer_Freiheit_Broschuere_Stand_Dezember_2010.pdf $>$. Acesso em: 15 set. 2015.

THF 100\%. Tempelhofer Feld Gezetz. 2014. Disponível em: <http://www.thf100.de/tl_files/ thf100/download/gesetz/THFG_Gesetz-_und_Verordnungsblatt_15-14-s189-s196. pdf>. Acesso em: 15 set. 2015. 